\title{
Subulura halli (Ascaridida: Subuluridae) from the endangered great bustard Otis tarda Linnaeus (Aves: Gruiformes) in China
}

\author{
Li-Qiang Du${ }^{1}$, Zhen $\mathrm{Xu}^{2}$, Shun-Cai $\mathrm{Li}^{1}$ and Liang $\mathrm{Li}^{3}$ \\ ${ }^{1}$ College of Life Science and Technology, Hebei Normal University of Science \& Technology, Qinhuangdao, Hebei Province, \\ China; \\ ${ }^{2}$ Medical College of Hebei University of Engineering, Handan, Hebei Province, China; \\ ${ }^{3}$ Key Laboratory of Animal Physiology, Biochemistry and Molecular Biology of Hebei Province, College of Life Science, Hebei \\ Normal University, Shijiazhuang, Hebei Province, China
}

\begin{abstract}
Subulurid nematodes identified as Subulura halli Barreto, 1918 were collected from the endangered bird Otis tarda Linnaeus (Gruiformes: Otididae) in China. A detailed redescription of the hitherto poorly known species is presented using both light and, for the first time, scanning electron microscopy. Previously unreported and erroneous morphological features of taxonomic significance are revealed. This species can be readily distinguished from its congeners by the relatively long oesophagus (1.47-1.92 mm long, representing 10.6-16.9\% of body length), the number and arrangement of male caudal papillae (11 pairs in total, arranged as five pairs of precloacal and six pairs of postcloacal papillae), the equal length of spicules (1.35-1.52 $\mathrm{mm}$ long, representing $10.7-13.7 \%$ of body length) and the presence of a small medioventral, precloacal papilla in the male.
\end{abstract}

Keywords: Nematoda, redescription, morphology, taxonomy, scanning electron microscopy, Otididae, endangered birds, Palaearctic Region

The great bustard Otis tarda Linnaeus (Gruiformes: Otididae) is a large-sized, predominantly herbivorous, gregarious species, which is mainly distributed in the temperate regions of Europe and Asia, including Portugal, Spain, Hungary, Turkey, Russia, China, and Mongolia (Morales and Martin 2002, Palacín and Alonso 2008, Alonso and Palacín 2010). Otis tarda is considered as vulnerable globally due to the rapid population reductions owing to the loss, degradation and fragmentation of its habitat, as well as hunting (Butchart and Symes 2012). The latest estimate of the global population of the great bustard is 44 100-57000 individuals (Alonso and Palacín 2010). This species is listed in CITES Appendix II and also listed as a first-class state protected animal in China.

However, the helminth parasites of this bird are still poorly known. To our knowledge, only Mediorhynchus taeniatus Linstow, 1901 (Acanthocephala), Schistometra conoides (Bloch, 1782) and Idiogenes otidis Krabbe, 1867 (Cestoda), Aprocta orbitalis Linstow, 1901, Oxyspirura hispanica Yeh 1957, Subulura halli Barreto, 1918 and Heterakis gallinarum (Schrank, 1788) (Nematoda) have previously been reported parasitic in $O$. tarda (see Li 1933, Yeh 1957, Wu 1973, Larchenko and Sonin 1974, Gomez 1981, Junker and Boomker 2007).

During a helminthological survey of endangered birds in China in 1990, subulurid nematodes were col- lected from the small intestine of the great bustard from Chengde, Hebei Province. Morphologically, the adult nematodes were identified as a hitherto poorly known species Subulura halli Barreto, 1918. This species is redescribed herein using light microscopy and, for the first time, scanning electron microscopy based on the newly collected material.

\section{MATERIALS AND METHODS}

A dead great bustard was dissected and examined for parasites in 1990 from Chengde, Hebei Province, China. Nematodes recovered from the small intestine of this host were washed in physiological saline and then fixed and stored in $70 \%$ ethanol until studied. For light microscopical examination, the nematodes were cleared in lactophenol. Drawings were made with the aid of a Nikon microscope drawing attachment. For scanning electron microscopy (SEM), two selected specimens (one male and one female) were fixed in cold $4 \%$ formaldehyde solution, post-fixed in $1 \%$ osmium tetroxide, dehydrated via an ethanol series and acetone, and then critical point dried. The specimens were coated with gold and examined using a Hitachi S-570 scanning electron microscope at an accelerating voltage of $15 \mathrm{kV}$.

Measurements (range, followed by mean in parentheses) are given in micrometres unless otherwise indicated. Voucher specimens were deposited in College of Life Science, Hebei Normal University, Hebei Province, People's Republic of China (HBNU) and Natural History Museum, London, UK (NHMUK). 


\section{RESULTS AND DISCUSSION}

Redescription of Subulura halli Barreto, 1918

Figs. 1-3

Syn.: Subulura forcipata (Rudolphi, 1819) of Seurat (1914), in part

General. Small, whitish to yellowish nematodes. $\mathrm{Cu}$ ticle with fine transverse striations. Maximum width of body at about mid-body. Anterior end of body usually bent dorsally. Cervical alae well developed, extending from base of cephalic plate to level of posterior end of oesophagus or a small distance behind it in male (cervical alae extending to a small distance behind vulva in female) (Figs. 1B,D,E, 3A,C). Cephalic plate without developed lips. Oral aperture simple, hexagonal or approximately circular, surrounded by four ovoid, submedial double papillae, two prominent lateral amphids (Figs. 1E, 2A,B, 3A,B). Buccal cavity cylindrical, with well sclerotized walls. Pharynx composed of three muscular portions, each composed of three lobes (peripheral lobe $=$ previously reported as second buccal cavity, radial and chordal lobes = previously reported as tooth-like structure according to Inglis 1958), twisted to make pharynx form a helicoidal structure (Figs. 1B,E, 2A,B, 3A,B). Oesophagus terminating in conspicuous bulb (Fig. 1A,D). Caudal alae absent. Tail of both sexes conical, with pointed tip (Figs. 1F,I,J, 2C,D, 3G).

Male (based on six mature specimens): Body 9.02-13.0 (11.0) mm long, maximum width 368-417 (392). Buccal cavity 25-39 (34) deep, maximum width 44-65 (51). Oesophagus with its bulb 1.52-1.92 (1.71) mm long, representing $12.8-16.9 \%$ (15.5\%) of body length; its bulb 196-315 (235) long, maximum width 210-294 (243) (Fig. 1A,D). Nerve-ring and excretory pore 294-373 (336) and 490-637 (555), respectively, from anterior extremity (Fig. 1A,D).

Posterior end of body curved ventrally. Precloacal pseudosucker without ornamentation, 472-623 (513) long from cloaca (measured from centre of pseudosucker) (Figs. 1I, 2F). Spicules well sclerotized, alate, pointed at distal end, of almost equal length, 1.35-1.52 (1.40) mm long, representing $10.7-13.7 \%(12.2 \%)$ of body length (Fig. 1G,I). Gubernaculum banana-shaped in lateral view, 132-167 (141) long (Figs. 1C,I, 2C,D, 3F).

Caudal papillae 11 pairs in total, arranged as follows: five pairs precloacal, with first pair of precloacal papillae situated at level of centre of precloacal pseudosucker and last two pairs of paracloacal rather close to cloaca, and six pairs of postcloacal papillae arranged as five pairs ventrolateral, with fourth pair dorsolateral (? phasmids) and fifth pair very small (Figs. 1F,I, 2C-F, 3F,G). Small, single precloacal papilla small, medioventral (Figs. 2C, 3F). Tail 332-407 (393) long.

Female (based on seven gravid specimens): Body 12.3 14.3 (13.5) $\mathrm{mm}$ long, maximum width 470-490 (482). Buccal cavity 29-39 (36) deep, maximum width 44-59
(49). Oesophagus with its bulb 1.47-1.91 (1.62) mm long, representing $10.6-13.4 \%(12.0 \%)$ of body length; its bulb 221-324 (245) long, maximum width 216-325 (261). Nerve-ring and excretory pore 319-368 (339) and 470-588 (515), respectively, from anterior extremity.

Vulva slit-like, near middle of body, 5.34-6.17 (5.70) $\mathrm{mm}$ from anterior extremity, 41.7-44.4\% (42.9\%) of body length (Figs. 1H, 3C,D). Vagina directed posteriorly from vulva. Eggs suboval, embryonated, 44-64 (48) $\times 39-49(43)(\mathrm{n}=21)$ (Fig. 1K). Anus with one protruding lip (Fig. 3E). Tail very long, 1.42-1.57 (1.50) $\mathrm{mm}$ in length (Fig. 1J).

Type host: Little bustard, Otis tetrax (Linnaeus) (syn. Tetrax tetrax Linnaeus) (Gruiformes: Otididae).

Other host: Great bustard, Otis tarda Linnaeus (Gruiformes: Otididae).

Site of infection: Small intestine.

Type locality: Algeria.

Other localities: Chengde, Hebei Province, and Beijing, China.

Rate of infection: Single bird examined with intensity 13 specimens.

Voucher specimens: 5 males and 6 females (HBNUB1301L), 1 male and 1 female (NHMUK 2013.7.2.3-4).

Remarks. The genus Subulura Molin, 1860 currently includes over 70 nominal species, many of which were considered as species incertae sedis by Inglis (1958) because of the poorly known information on the structure of the head. The adults of Subulura are frequently found in the digestive tract of birds and mammals, and can also occur in lizards (Barreto 1918, Cram 1927, Ilyas 1982, Diouf et al. 1998, Vicente et al. 2000, Ubelaker et al. 2007, Ming and Zhang 2010). Based on the cephalic structures, especially the presence or absence of labial lobes and interlabia surrounding the oral aperture, Subulura falls into three subgenera, Subulura Molin, 1860, Murisubulara Quentin, 1969 and Tepuinema Díaz-Ungía, 1964, according to Chabaud (1978). Barreto (1918) supposed that the morphology of some of the specimens of $S$. forcipata (Rudolphi, 1819) identified by Seurat (1914), which were collected from the little bustard Tetrax tetrax Linnaeus (=Otis tetrax) (Gruiformes: Otididae) in Algeria, was different from the real $S$. forcipata and represented a distinct species. Therefore, he proposed a new name Subulura hal$l i$ for these nematodes (Barreto 1918, Cram 1927). Subsequently, Li (1933) reported this species from the great bustard Otis tarda Linnaeus (Gruiformes: Otididae) in China.

Morphological description of specimens of S. halli, who considered them to belong to $S$. forcipata, by Seurat (1914) was somewhat brief and provided too few illustrations by modern standards. Nonetheless, several critical diagnostic characters are figured or mentioned, such as the position of the precloacal pseudosucker and vulva, the length of oesophagus and spicules, the number and arrangement of caudal papillae, by which we can readily 


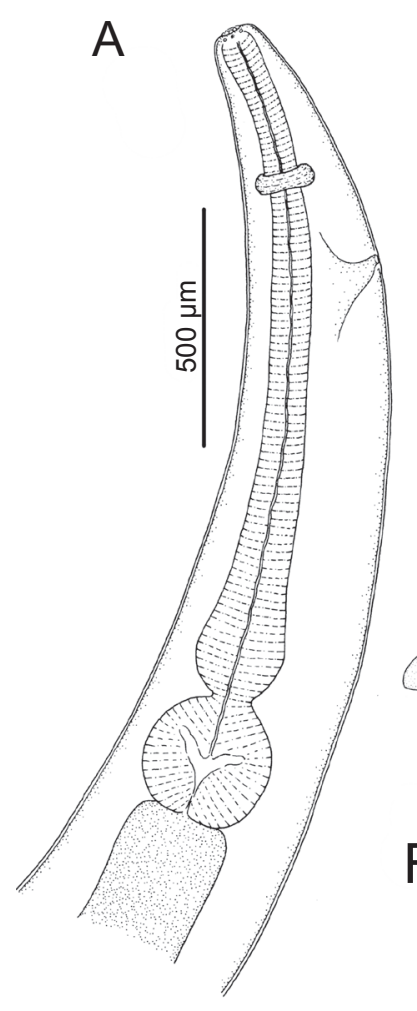

B
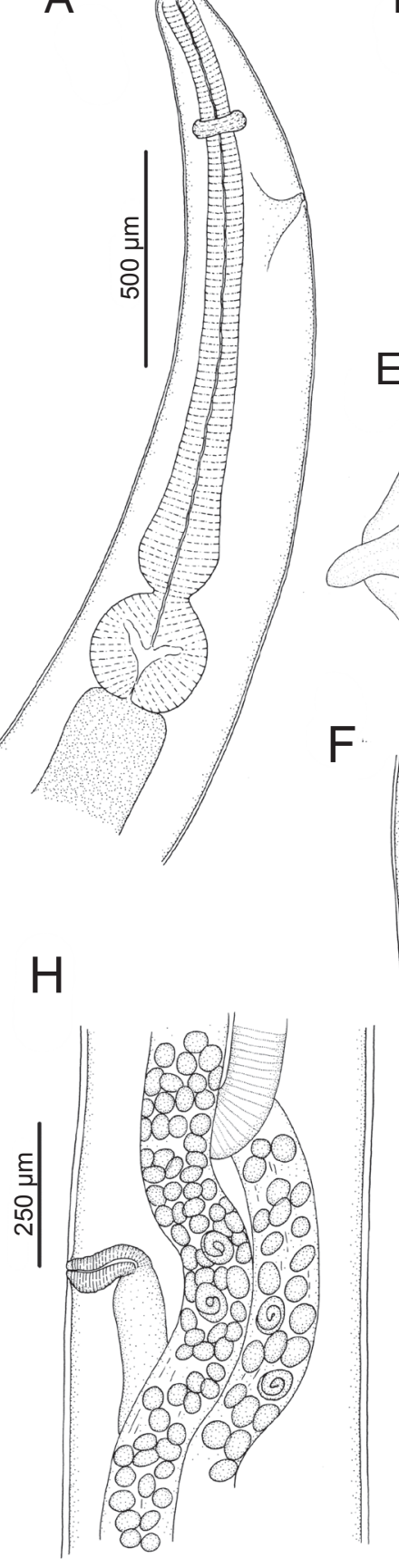

K

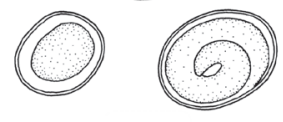

$120 \mu \mathrm{m}$

E

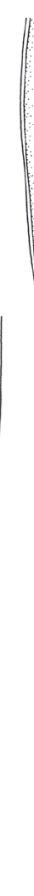

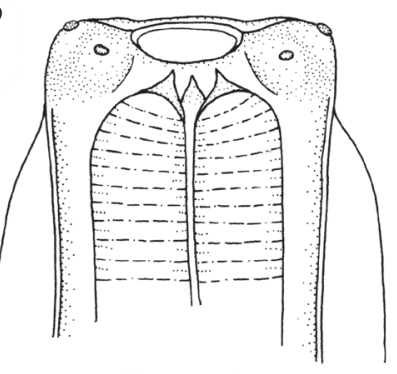
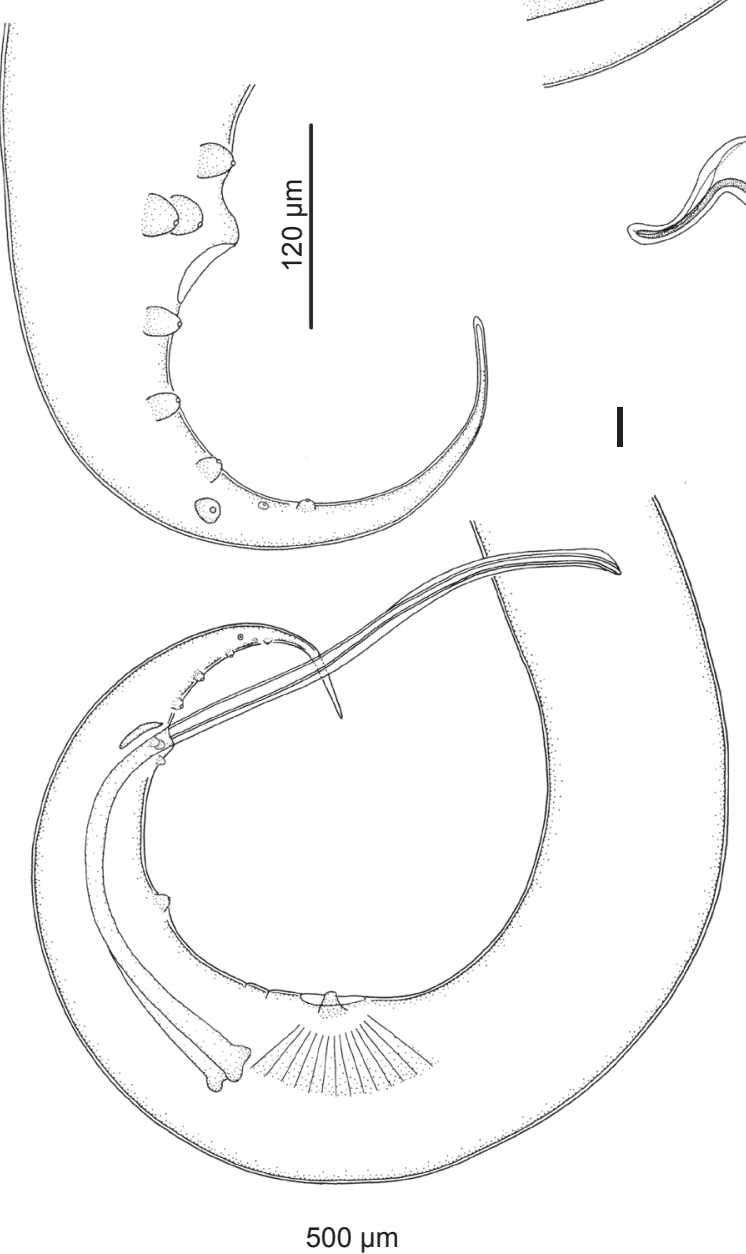

C

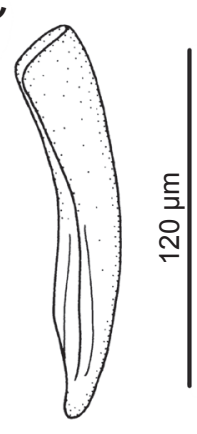

D

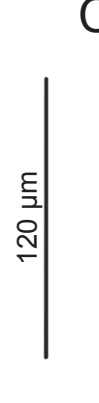

D

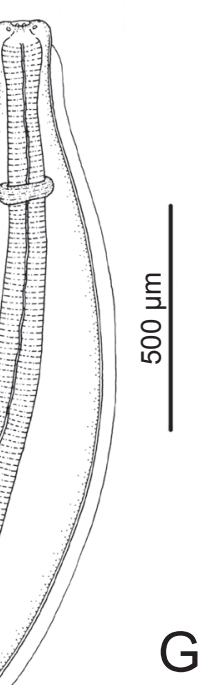

G

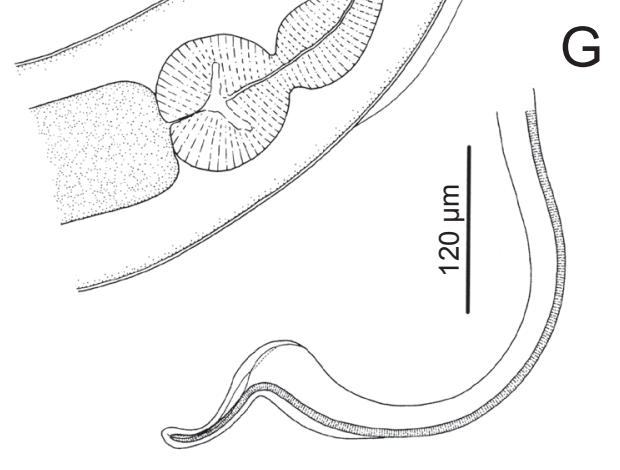

\section{.}



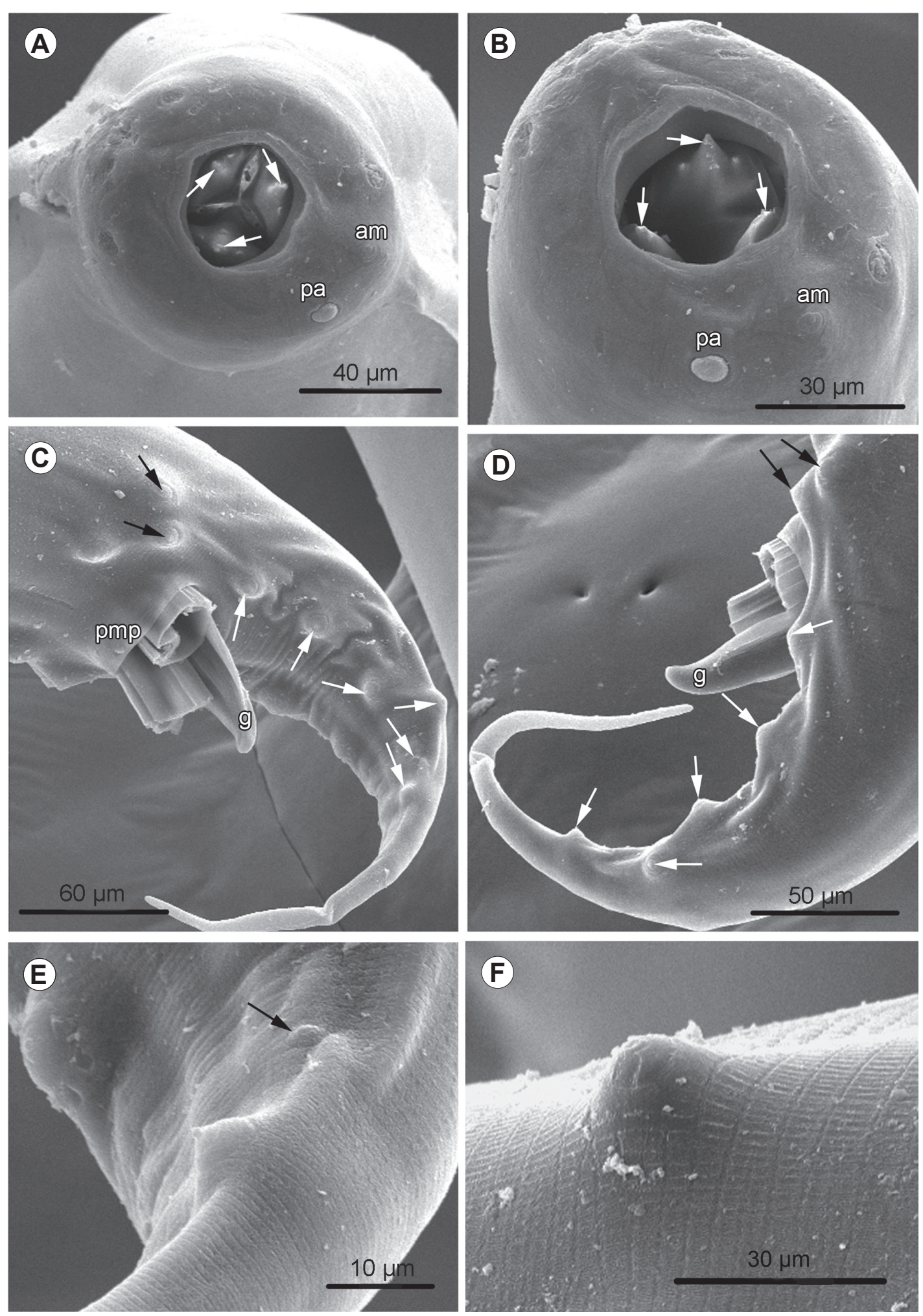

Fig. 2. Scanning electron micrographs of male of Subulura halli Barreto, 1918 from Otis tarda Linnaeus in China. A, B - cephalic extremity, apical view; arrows show the anterior end of the pharynx that bears an elaborate arrangement of tooth-like structures; C - posterior end of body, ventral view; black arrows show the last 2 precloacal papillae close to cloaca, white arrows show postcloacal papillae (spicules broken); D - posterior end of body, lateral view; black arrows show last 2 precloacal papillae rather close to cloaca, white arrows show postcloacal papillae (spicules broken); $\mathbf{E}$ - last two postcloacal papillae; black arrow show $5^{\text {th }}$ small postcloacal papilla; $\mathbf{F}$ - region of precloacal pseudosucker and magnified image of $1^{\text {st }}$ precloacal papilla. Abbreviations: am - lateral amphid; g - gubernaculum; pa - submedial double papillae; pmp - medioventral precloacal papilla. 

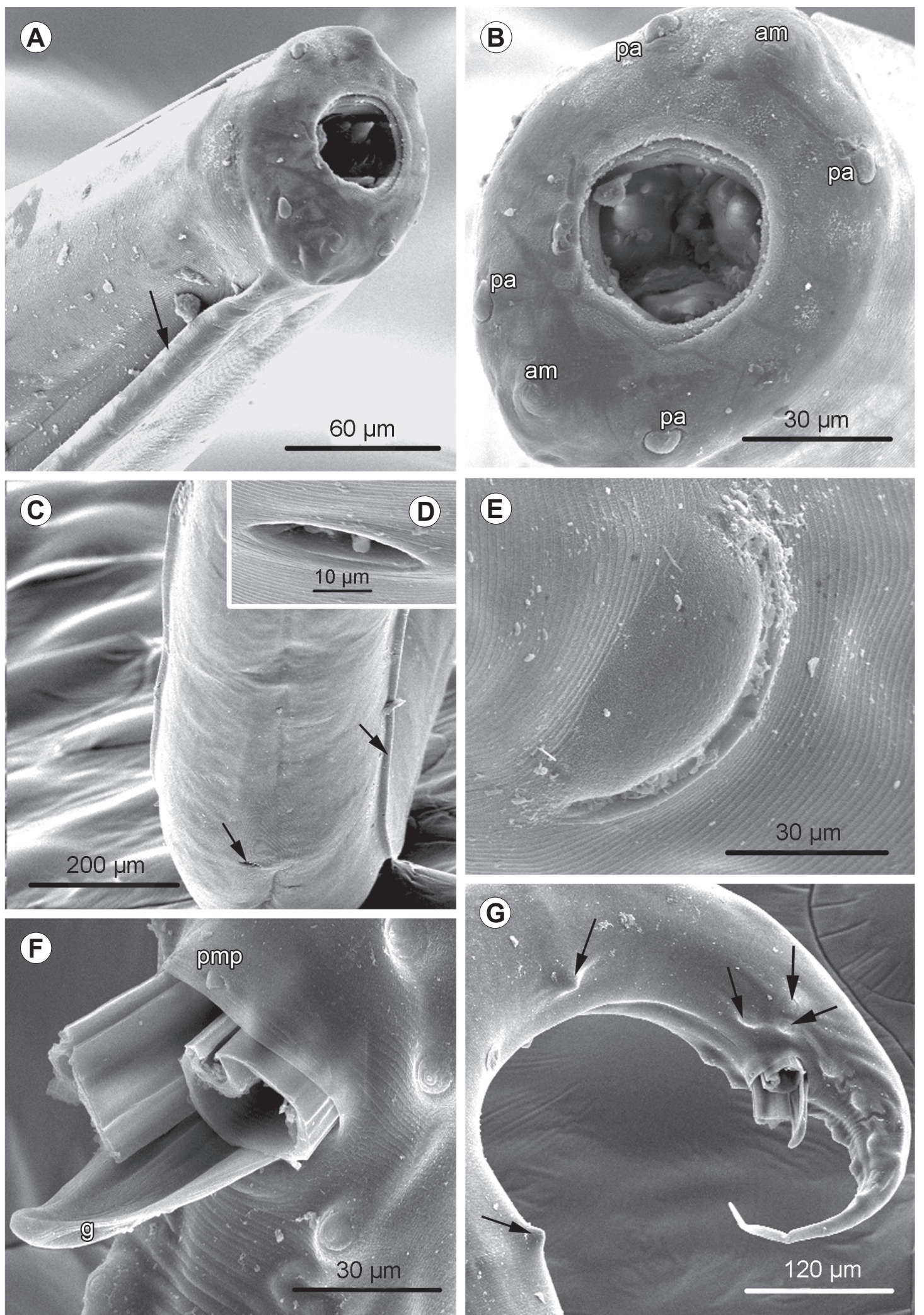

Fig. 3. Scanning electron micrographs of Subulura halli Barreto, 1918 from Otis tarda Linnaeus in China. A-anterior part of female, subapical view; lateral ala arrowed; B - cephalic end of female, apical view; $\mathbf{C}$ - region of vulva, ventral view; lateral ala and vulva arrowed; D - magnified image of vulva; $\mathbf{E}$ - anus of female, ventral view; $\mathbf{F}$ - region of cloaca of male (spicules broken), ventral view; $\mathbf{G}$ - posterior end of male (spicules broken), subventral view; precloacal papillae arrowed. Abbreviations: am - lateral amphid; $\mathrm{g}$ - gubernaculum; $\mathrm{pa}$ - submedial double papillae; pmp - medio-ventral precloacal papilla. 
distinguish this species from its congeners. It is thus not necessary to identify this species by examining the type material, which has been deposited in the Muséum National d'Histoire Naturelle, Paris for more or less 100 years and in poor condition. Moreover, the taxonomy of Subulura, and especially delimitation of the genera or subgenera, are mainly based on cephalic structures. Currently, the most useful and practical method for studying of the cephalic structures of types in detail is to use SEM. Unfortunately, it is inevitable to destroy type specimens and this situation must be forbidden by the curator. Thus, we did not compare our present material with the types of $S$. halli.

However, the morphology and measurements of the present specimens are almost identical to the original description of $S$. halli by Seurat (1914; as $S$. forcipata) and later by $\mathrm{Li}$ (1933), including the body size, the position of the nerve-ring, excretory pore, precloacal pseudosucker and vulva, the length of the oesophagus and spicules, the arrangement of caudal papillae, and the morphology of the male and female tail. Furthermore, it should also be noted that the present specimens were collected from the congeneric hosts as $S$. halli and from the same host as those studied by Li (1933).

Consequently, we considered that our material should be conspecific with $S$. halli. However, the tail length of the male of present material is slightly shorter than reported by Seurat (1914; as S. forcipata) and later by Li (1933); 0.33-0.41 $\mathrm{mm}$ in the present material vs $0.50 \mathrm{~mm}$ and $0.43-0.49 \mathrm{~mm}$, respectively, in material of Seurat 1914 and Li 1933 material. This morphometric difference should be considered as intraspecific variability, possibly owing to the different hosts or geographical locations.

The present study provides the first data on the detailed structure of the poorly known nematode using scanning electron microscopy (SEM), which made it possible to observe previously unreported morphological features of taxonomic significance and to correct some erroneous information. Inglis (1958) considered $S$. halli as a species incertae sedis because of its insufficiently known structures of the head.

In our material we observed the oral aperture to be simple, hexagonal or nearly circular (without labial lobes and interlabia), the buccal cavity circular in transverse section, pharyngeal portions lobed and twisted, cervical alae well developed, precloacal pseudosucker without any cuticular ornament and both spicules fully sclerotized. All of these characters clearly show that $S$. halli should belong to the subgenus Subulura. Seurat (1914) reported 11 pairs of caudal papillae (five pairs precloacal), whereas Li (1933) stated that there were only 10 pairs of caudal papillae and one pair of phasmids in his material.

The present SEM observations show 11 pairs, which are arranged as five pairs of precloacal (the last two pairs of paracloacal rather close to the cloaca) and six pairs of postcloacal (five pairs ventrolateral and the fourth pair dorsolateral) papillae. In fact, it is very difficult to decide whether the fourth pair of dorsolateral postcloacal papillae are phasmids or caudal papillae (based on their position, they seem to be phasmids rather than papillae).

Moreover, neither Seurat (1914) nor Li (1933) reported whether there was any medioventral precloacal papilla in the male, whereas, using SEM, we observed one small, single, medioventral, precloacal papilla in our specimens (Figs. 2C, 3F). As far as we are aware, none of Subulura spp. has previously been reported to possess this structure. Seurat (1914) reported narrow caudal alae to be present. However, in our material we could not observe this structure. Li (1933) also reported six labial papillae around the hexagonal mouth, in addition to four submedial double papillae and two lateral amphids. However, we only observed the hexagonal mouth surrounded by four submedial double papillae and two lateral amphids (there are no labial papillae) by SEM examination (see Figs. 2A,B, 3A,B).

Within the genus Subulura, only $S$. rima (Linstow, 1906) was reported from birds of the family Otididae (Cram 1927). Subulura halli differs from S. rima by having much longer spicules $(1.35-1.52 \mathrm{~mm}$ in the former $v s$ 0.70 and $0.84 \mathrm{~mm}$ in the latter) and different number and arrangement of caudal papillae (11 pairs in total, arranged as five pairs of precloacal and six pairs of postcloacal papillae in $S$. halli vs nine pairs in total, arranged as four pairs precloacal and five pairs postcloacal in $S$. rima).

In fact, out of the species of Subulura that occur in birds, $S$. halli, which is typified by having a relatively long oesophagus (length over $1.40 \mathrm{~mm}$ ) and the equal length of spicules (over $1.30 \mathrm{~mm}$ ), is similar only to $S$. leprincei (Gendre, 1909) from Caprimulgus aegyptius Lichtenstein, C. fossii Hartlaub and Macrodipteryx longipennis (Shaw) (Caprimulgiformes: Caprimulgidae) (Cram 1927).

However, S. halli can be readily distinguished from $S$. leprincei by the different number and arrangement of caudal papillae, especially the number of papillae and position of the first pair of precloacal ones (11 pairs in total and the first pair of precloacal papillae situated at the level of the centre of the precloacal pseudosucker in $S$. halli vs 13 pairs in total and the first pair of precloacal papillae situated at the level of the anterior margin of the precloacal pseudosucker in the latter species), the absence of caudal alae (caudal alae well developed in S. leprincei) and the presence of medioventral, precloacal papilla in the male in the former species ( $v s$ its absence in the latter).

Acknowledgements. This study was supported by the National Natural Science Foundation of China (Project No. 31101615), Natural Science Foundation of Hebei Province (No. C2012205007), China Postdoctoral Science Foundation (No. 2012M520593), Natural Science Foundation of Hebei Education Department (No. Y2012012), Postdoctoral Research Projects Merit Subsidy of Human Resources and Social Security Department of Hebei Province, Natural Science Foundation and Biology Postdoctoral Programme of Hebei Normal University (Nos. L2010B13 and 111008). 


\section{REFERENCES}

Butchart S., Symes A. (Eds.) 2012: BirdLife International; Otis tarda. In: IUCN 2012. IUCN Red List of Threatened Species. World Wide Web electronic publication, www.iucnredlist.org/ details/106002760/0, 02/2012.

Alonso J.C., Palacín C. 2010: The world status and population trends of the great bustard (Otis tarda): 2010 update. Chin. Birds 1: 141-147.

Barreto A.L.B. 1918: Revisão da sub-familia Subulurinae Travassos, 1914. Typographia Leuzinger, Rio Janeiro, 161 pp. + 23 Plts.

Chabaud A.G. 1978: CIH Keys to the Nematode Parasites of Vertebrates. No. 6. Keys to Genera of the Superfamilies Cosmocercoidea, Seuratoidea, Heterakoidea and Subuluroidea. Commonwealth Agricultural Bureaux, Farnham Royal, 71 pp.

CrAm E.B. 1927: Bird parasites of the nematode suborders Strongylata, Ascaridita and Spirurata. U.S. Nat. Mus. Bull. 140: $1-465$.

Diouf M., BÂ C.T., Marchand B., Faye O. 1998: Subulura saloumensis $\mathrm{n}$. sp. (Nematoda, Subuluroidea) from four species of rodents in Senegal. J. Parasitol. 84: 566-570.

Gomez I. 1981: Schistometra conoides (Bloch, 1782) Skrjabin, 1914, intestinal parasites of Otis tarda L. Rev. Iber. Parasitol. 41: $163-174$

Ilyas R. 1982: A key to the sixty two (62) species of Subulura Molin, 1860 and a new species of Subulura from Turdoides somervillei. Riv. Parassitol 43: 33-41.

INGLIS W.G. 1958: The comparative anatomy of the subulurid head (Nematoda): with a consideration of its systematic importance. Proc. Zool. Soc. Lond. 130: 577-604.

Junker K., Boomker J. 2007: A check list of the helminths of guineafowls (Numididae) and a host list of these parasites. Onderstepoort J. Vet. Res. 74: 315-337.

Received 20 May 2013
LARChEnko T.T., Sonin M.D. 1974: [The nematodes of bustards (Otididae) in Tuva ASSR.] Trudy GELAN 24: 76-83. (In Russian.)

Li H.-C. 1933: Report on a collection of parasitic nematodes mainly from North China. Part III. Oxyuroidea. Chin. Med. J. 47: 1307-1325.

Ming Z., Zhang, L.-P. 2010: Subulura (Murisubulura) tanjinensis sp. nov. (Nematoda, Subuluroidea) from Eutamias sibiricus (Laxmann) (Rodentia) in Tianjin, China. Acta Parasitol. 55: 133-137.

Morales M.B., Martin C.A. 2002: Great bustard Otis tarda. BWP Update 4: 217-232.

Palacín C., Alonso J.C. 2008: An updated estimate of the world status and population trends of the great bustard Otis tarda. Ardeola 55: 13-25.

Seurat L.G. 1914: Sur quelques Hétérakis d'Oiseaux. Bull. Soc. d'Hist. Nat. Afr. Nord. 6: 195-205.

Ubelaker J.E., Easter-Taylor R., Marshall A., Duszynski D.W. 2007: A new species of Subulura (Nematoda: Subuluroidea) from ground squirrels, Spermophilus spilosoma Bennett, 1833, in New Mexico. J. Parasitol. 93: 1199-1201.

Vicente J.J., Sluys M.V., Fontes A.F., Kiefer M.C. 2000: Subulura lacertilia sp. n. Nematoda, Subuluridae) parasitizing the Brazilian lizard Tropidurus nanuzae Rodrigues (Lacertilia, Tropiduridae). Rev. Brasil. Zool. 17: 1065-1068.

Wu S.-Q. 1973: [Helminths of birds and wild animals from LinTsan Prefecture, Yunnan Province, China (I. Parasitic nematodes of birds).] Acta. Zool. Sin. 19: 341-353. (In Chinese, with English summary.)

YEH L.-S. 1957: A collection of helminths from the great bustard, Otis tarda from Spain, with a description of a new species of Oxyspirura (Nematoda). Proc. Zool. Soc. Lond. 128: 279-285.

Accepted 3 July 2013 